\title{
MORPHOLOGICAL AND IMMUNOLOGICAL CHARACTERIZATION OF ANTHRAX VACCINE IN CATTLE
}

\author{
M. Dipti, M. M. Rashid, M. J. Ferdoush, P. Roy, M. A. H. N. A. Khan and M. M. Hossain* \\ Department of Pathology, Faculty of Veterinary Science, Bangladesh Agricultural University, Mymensingh- \\ 2202, Bangladesh
}

\begin{abstract}
Anthrax is a zoonotic disease caused by the bacterium Bacillus anthracis that normally affects animals, especially ruminants (such as cattle, goats, sheep, and horses) and humans. This study was planned to characterize the morphology of anthrax vaccine bacteria by using Gram's stain, polychrome methylene blue stain, culture on nutrient agar and nutrient broth media and to determine the immunological status of this vaccine by indirect ELISA and slide agglutination test in cattle. Antibiotic sensitivity test of vaccine strain of bacteria was also done. This study provided evidence that vaccine strain of Bacillus anthracis was gram-positive rod-shaped bacteria appeared as single to short-chained bacilli with blunted ends. Serum from anthrax vaccinated cattle agglutinated anthrax antigen on Day $30(+++$ within 5 min and ++ within 7 min at 1:100 dilution of test sera) and Day 90 (+++ within 5 min at 1:100 dilution of test sera) of post immunization. Immunization of cattle with anthrax vaccine generated high level of anti-anthrax IgG antibody response at Day $30(0.789 \pm 0.014)$ of post immunization and reached its peak at Day $90(0.991 \pm 0.047)$. This study also provided evidence that anthrax vaccine bacteria were sensitive to penicillin, streptomycin, amoxicillin and kenamycin. It may be recommended that the anthrax vaccine currently in use in Bangladesh is proved to be effective in term of morphology of Bacillus antharis and raising anti anthrax $\mathrm{IgG}$ antibody response in cattle with no side effect.
\end{abstract}

Key words: Characterization, anthrax, vaccine

\section{INTRODUCTION}

Bacillus anthracis, the etiological agent of anthrax, is a gram-positive spore forming bacterium. Anthrax can affect a wide range of species, but occurs primarily in ruminants including cattle, sheep and goats. Though the life cycle of $B$. anthracis is not completely understood, it is thought to be an obligate pathogen with replication occurring only in permissible hosts. Spores are either ingested or inhaled during grazing and the spores germinate and bacteria subsequently replicate to very high numbers. Once the infection reaches the systemic stage, the animal soon succumbs to the infection. Following death, vegetative bacilli are shed into the environment and sporulation is induced producing a pool of infectious spores that are available to infect new hosts. There are three forms of illness in cattle such as per acute: sudden death and rapidly fatal course; acute: high temp. $\left(107^{\circ} \mathrm{C}\right)$, bloody discharge from orifices and sub acute-chronic: edematous swelling. Anthrax is a zoonotic disease (disease that can affect both man and animals). In humans it can take five forms: cutaneous, respiratory, intestinal, septicemic and meningial. The cutaneous or skin form occurs when anthrax spores invade a cut or abrasion. Initially the site will itch followed by swelling and discoloration of the affected area (Weiss et al., 2007, OIE, 2008).

Reported and published findings shows that there were 14 outbreak and 140 animals and 273 human cases were affected by anthrax during August 2009-October 2010 in Bangladesh. Anthrax in animals was prevailing in Bangladesh but it has got more importance after human was affected by handling anthrax affected cattle and goat. However for control of anthrax, anthrax spore vaccine, prepared by Livestock Research Institute (LRI), Mohakhali, Dhaka is now being used according to the instruction of LRI. This vaccine can induce immunity against anthrax disease for six months according to the instruction of Livestock Research Institute (LRI). Laboratory data for anthrax vaccine efficacy are insufficient for each lot or batch of produced vaccines. To enrich the data of immunological response in cattle, more intensive works need to be carried out. Therefore, the study was planned to determine the morphology of anthrax vaccine bacteria and immune response of anthrax vaccine in cattle after vaccination.

*Corresponding e-mail address: mmhossain04@yahoo.com.au 


\section{Dipti and others}

\section{MATERIALS AND METHODS}

The research work was performed at the Department of Pathology, Faculty of Veterinary Science, Bangladesh Agricultural University, Mymensingh during the period from June 2012 to May 2013.

\section{Collection of anthrax vaccine}

Anthrax vaccine supplied as $100 \mathrm{ml}$ was prepared by Livestock Research Institute (LRI), Mohakhali, Dhaka. Five bottles of vaccine were collected to observe the immunological response in cattle after vaccination. The master-seed of this vaccine is living spores of the non-capsulated attenuated Sterne F-24 strain of B. anthracis originated at Australia.

\section{Selection of experimental animals}

Apparently healthy and previously unvaccinated dairy cattle of average 3-6 years old and body weight varied from $250-400 \mathrm{~kg}$ from climatic change prone delta region of Satkhira $(\mathrm{n}=5)$, Khulna $(\mathrm{n}=5)$ and semi changeable climatic zone of Pabna ( $n=5)$, Tangail $(n=5)$ and Mymensingh (BAU Animal Nutrition Shed) ( $n=5)$ were used in this study. The vaccines were injected $1 \mathrm{ml}$ subcutaneously $(\mathrm{S} / \mathrm{C})$ according to instruction of manufacturer and sera were collected at Day 0, Day 30 and Day 90 after vaccination.

\section{Collection of serum from experimental cattle}

About $5 \mathrm{ml}$ blood was collected in $15 \mathrm{ml}$ Falcon tube from jugular vein using disposable plastic syringe. The blood in Falcon tube was left to clot overnight at slanting position in refrigerator at $4{ }^{\circ} \mathrm{C}$ and the sera were decanted into Eppendorf tubes and the sera containing remaining cells were centrifuged at $2000 \mathrm{rpm}$ for 10 minutes. Again sera were transferred in Eppendorf tubes and stored at $-20^{\circ} \mathrm{C}$ until use.

\section{Morphological characterization of Bacillus anthracis by Gram's staining method}

A small amount of bacterial colony was taken on clean glass slide. One drop of water was added and mixed properly. Later the slides were first air dried and then fixed with gentle heat. Ammonium oxalate/crystal violet was applied on the smear of slide for $2 \mathrm{~min}$. The slide was washed in water. Gram's iodine was applied for 2 min. Iodine was applied on slide but did not wash. The slide was decolorized with a few drops of acetone for 5-15 Seconds. The slides were washed thoroughly in water. These were stained by counter stain with $0.5 \%$ safranin for $2 \mathrm{~min}$. The slides were washed and dried in air. Then the slides were examined with immersion oil with high power objectives. Personal protection was taken to culture anthrax vaccine bacteria. The culture of bacteria in broth and agar from anthrax vaccine were put into 10\% formalin for 24 hours before disposal (Fatema, 2011). All these operations were carried out in BSL2 cabinet in the Department of Pathology.

\section{Staining with $1 \%$ polychrome methylene blue (McFadyean reaction)}

A small colony was picked up from colonies of nutrient agar on glass slide and fixed up by gentle heating. A large drop of $1 \%$ polychrome methylene blue was put on the smear to cover it completely. The slide was left for 30-60 seconds and washed off in hypochlorite solution and air dried. Finally the slide examined under microscope with high power objective (100X) using immersion oil (OIE, 2008).

\section{Slide agglutination test to determine immunological response after anthrax vaccination in cattle}

The test was performed by placing a drop of diluted antigen and a drop of diluted serum on a slide. Then two drops were mixed slowly and kept at room temperature and examined every 5, 7, 10 and 15 minutes for evidence of clumping followed by microscopic examination. The same procedure was done for every sample and compared with negative serum. The agglutination results were graded as,,,++++++ \pm and - according to clump formation within $5 \mathrm{~min}, 7 \mathrm{~min}$, $10 \mathrm{~min}, 15 \mathrm{~min}$ and no clump formation (Fatema, 2011).

\section{Preparation of plate coating antigen for indirect ELISA \\ Antigen coating to ELISA plate}

Each well of a plate was coated with the antigen by pipetting $50 \mu 1$ of the antigen dilution and $50 \mu \mathrm{l}$ of PBS. The plate was covered with an adhesive plastic and incubated for 1 hour at $37^{\circ} \mathrm{C}$. The solution was removed by flicking the plate over a sink and wash was done in PBS-Tween-20 $(0.05 \%)$ for 3 times. The remaining drops were removed by patting the plate on a paper towel. 


\section{Blocking}

The remaining protein-binding sites in the coated wells was blocked by adding $150 \mu 1$ blocking buffer, per well. The plate was incubated at $37^{\circ} \mathrm{C}$ for 90 minutes. The plate was washed $3 \mathrm{X}$ with PBS, Tween-20 (0.05\%).

\section{Incubation with primary and secondary antibody}

One hundred microliter of diluted primary antibody was added to each well. The plate was incubated for 1 hours at $37^{\circ} \mathrm{C}$. The plate was washed $3 \mathrm{X}$ with PBS, Tween-20 $(0.05 \%)$. One hundred microliter of HRP labeled anti-bovine antibody (1:5000) was added to each well and incubated for $45 \mathrm{~min}$ at $37^{\circ} \mathrm{C}$. The plate was washed $3 \mathrm{X}$ with PBS.

\section{Detection}

TMB solution $100 \mu \mathrm{l}$ per well was added and incubated at room temperature in the dark for 15 mintues or until turn to green color. To stop the reaction, $50 \mu 110 \% \mathrm{H}_{2} \mathrm{SO}_{4}$ was added to each well which give yellow color. Then the plate was read at $450 \mathrm{~nm}$ (Fatema, 2011).

\section{Antibiotic sensitivity}

The tested $B$. anthracisorganisms were taken from nutrient agar in $15 \mathrm{ml}$ Falcon tube containing $10 \mathrm{ml}$ nutrient broth by a bacteriological loop and incubated for 14 hours at $37^{\circ} \mathrm{C}$. One hundred microliter nutrient broth containing $B$. anthracisorganisms were inoculated on the surface of an agar plate with a micropipette. Then the broth was uniformly spread over the nutrient agar by a sterile L-shaped spreader. Then the inoculums was let down to dry about 15 minutes and penicillin, streptomycin, amoxicillin and kenamycin discs were placed over it by gently pressing to ensure even contact with the medium and the plate was incubated for 18 hours at $37^{\circ} \mathrm{C}$. The zone of inhibition around the disc was observed. Sensitivity to penicillin, streptomycin, amoxicillin and kenamycin was indicated by a zone of inhibition of growth around the disc (OIE, 2008).

\section{RESULTS}

The study was carried out to characterize the morphology of anthrax vaccine bacteria as well as to determine the immunological features of this vaccine in cattle.

\section{Isolation and identification of anthrax bacteria (Bacillus anthracis) from anthrax vaccine}

In nutrient agar media, the colony characteristics of anthrax vaccine bacteria were flat or slightly convex with irregular edges (Figure1). Anthrax vaccine bacterial sediments were inoculated also in nutrient broth. In nutrient broth, anthrax vaccine bacteria produced turbidity or cotton wool like growth.

\section{Morphological characterization of Bacillus anthracis by Gram's staining method}

The morphology of Bacillus anthracis was gram-positive rod-shaped bacteria appeared as single to short-chained bacilli with blunted ends (Figure 2).

\section{McFdyean reaction with $1 \%$ polychrome methylene blue}

The blue-black bacilli were seen with pink amorphous capsule (suspicious) under microscope (100X objectives) with immersion oil (Figure 3)

\section{Slide agglutination test}

Table 3 describes the results of slide agglutination test of tested sera and anthrax vaccine bacteria. The antibody response of cattle of different region at Day 0 was very minimum (graded as \pm to + ). The antibody response started rising at Day 30 (graded as ++ to +++ ) (Figure. 8) until Day 90 (graded as +++ ) (Figure. 9). However, the striking difference of slide agglutination test was not found in cattle of Satkhira, Khulna (climatic change prone delta region) and of Pabna, Tangail and Mymensingh (semi changeable climatic zone) (Figures 4-7 and Table 1). 


\section{Dipti and others}

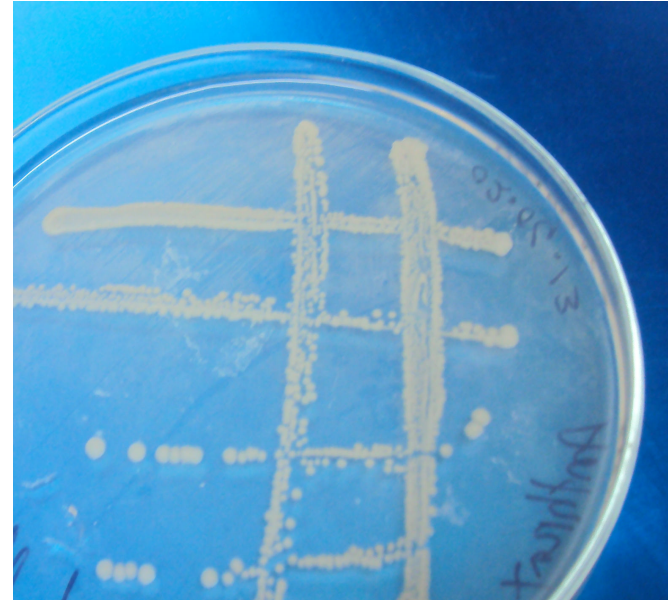

Figure 1. Subculture colonies of Bacillus anthracis from vaccine were found irregular, raised, dull, opaque and greyish white appearance on nutrient agar.

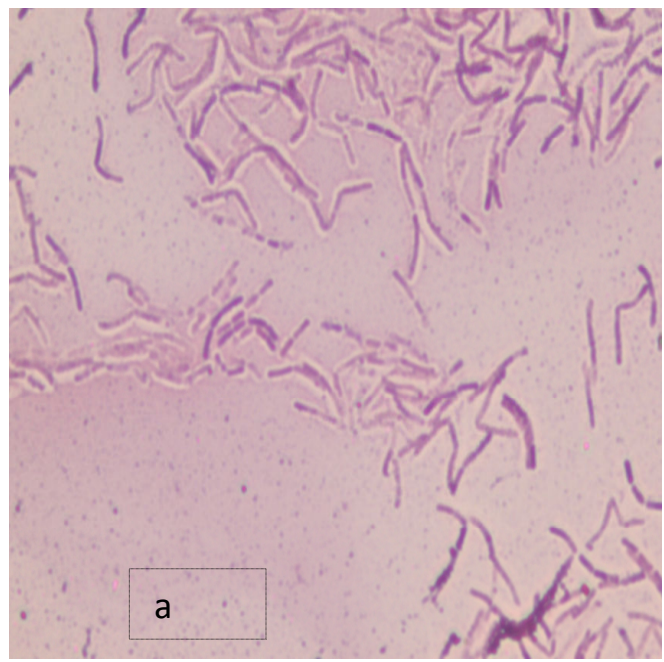

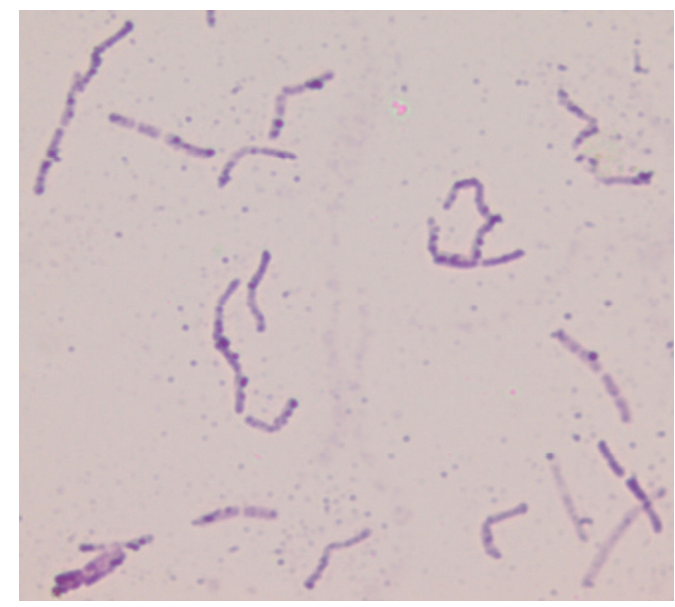

Figure 2. Smear prepared from anthrax vaccine sediment. Gram's stain showed gram-positive rod-shaped bacteria appear assingle to shortchained bacilli with blunted ends (100X).

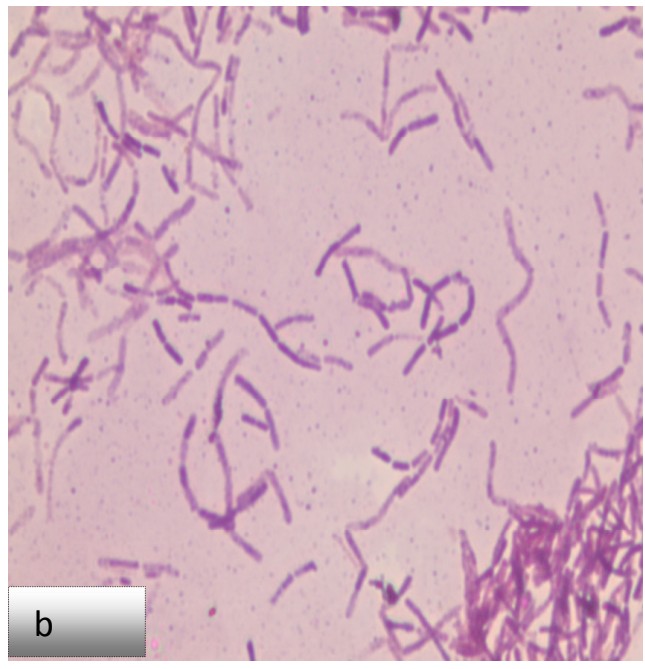

Figure 3:(a. taken from subculture I and b. taken from subculture II). Stained with 1\% polychrome methylene blue, the blue-black bacilli were seen with pink amorphous capsule (suspicious) under microscope (100X objectives) with immersion oil.

\section{Indirect ELISA}

Immunization against anthrax proved to be effective in terms of the specific IgG antibody response. The OD value was measured by using ELx800 reader with an interface filter of $450 \mathrm{~nm}$. A baseline OD value in ELISA protocol $0.41 \pm 0.12$ was considered as control/ negative response based on the average reactivity of control serum at 1:1000 dilution. The value above $0.41 \pm 0.12$ was considered as positive response and used in this study. The early immune response of anti-anthrax IgG response was detected in Day $30(0.79 \pm 0.01)$ of immunization and steadily increased up to Day $90\left(0.99 \pm_{0.05}\right)$ (Figure 8 and Table 2). 
Table 1. Average value of slide agglutination test of different experimental area (Satkhira, Khulna, Pabna, Tangail and Mymensingh)

\begin{tabular}{|cccc|}
\hline Sample & \multicolumn{3}{c|}{ Dilution of sera } \\
\hline *N $=25$ & $1: 10$ & $1: 100$ & $1: 1000$ \\
Day 0 & \pm & + & - \\
Day 30 & ++ to +++ & ++ & + \\
Day 90 & +++ & ++ & + \\
\hline
\end{tabular}

* From each region of experimental area 5 samples were tested and total sampleS were 25.

Legends

$+++=$ More agglutination/clumping within 5 minutes

$++=$ Agglutination within 7 minutes

$+=$ Less agglutination within 10 minutes

$\pm=$ Agglutination within 10-15 minutes

- = Absence of agglutination even after 15 minutes

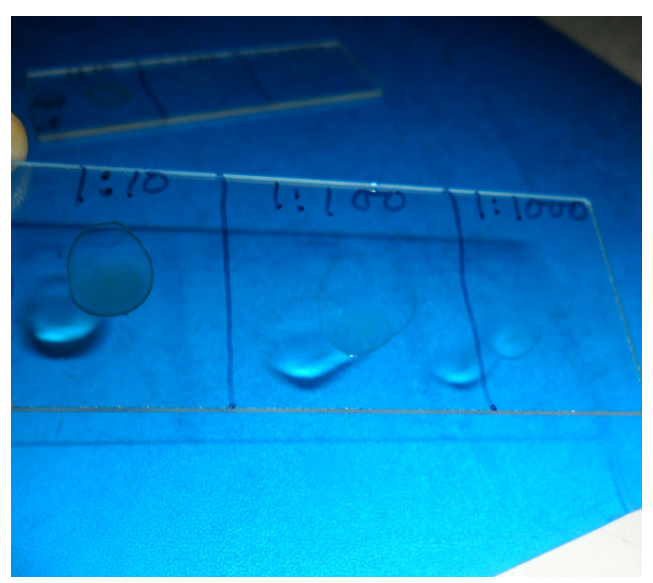

Figure 4. Slide agglutination test of sera of cattle at Day 0 ( Satkhira) showed no clump formation within $15 \mathrm{~min}$, graded as \pm to + in $1: 100$ dilutions.

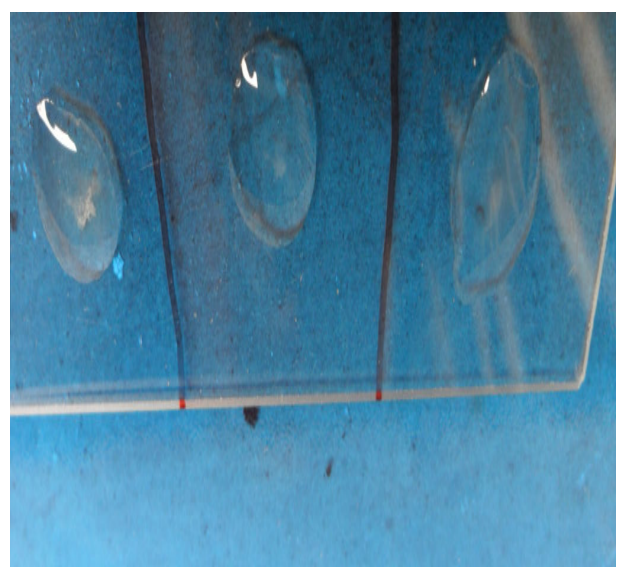

Figure5. Slide agglutination test of sera of cattle at Day 30 (Khulna) showed clump formation within 5 to $7 \mathrm{~min}$, graded as ++ to +++ in 1:100 dilutions.

\section{Sensitivity to antibiotics}

The antibiotic sensitivity test of anthrax vaccine bacteria was determined on nutrient agar plate against penicillin, streptomycin, amoxicillin and kenamycin. The zone of inhibition around the disc was observed. Sensitivity to penicillin, streptomycin, amoxicillin and kenamycin was indicated by a zone of inhibition of growth around the disc (Figure 9).

\section{DISCUSSION}

In nutrient agar media, the colony characteristics of anthrax vaccine bacteria were flat or slightly convex with irregular edges appearance. Similar observations were also made by Fatema (2011) and Murshidul (2012). In nutrient broth, anthrax vaccine bacteria produced turbidity which corroborated with the findings of Bergey et al. (1994).

Gram's stain showed typical morphology of Bacillus anthracis that was gram-positive rod-shaped bacteria appear as single to short-chained bacilli with blunted ends which were also observed by other investigators (Koch, 1876; Fatema, 2011; Murshidul, 2012). 


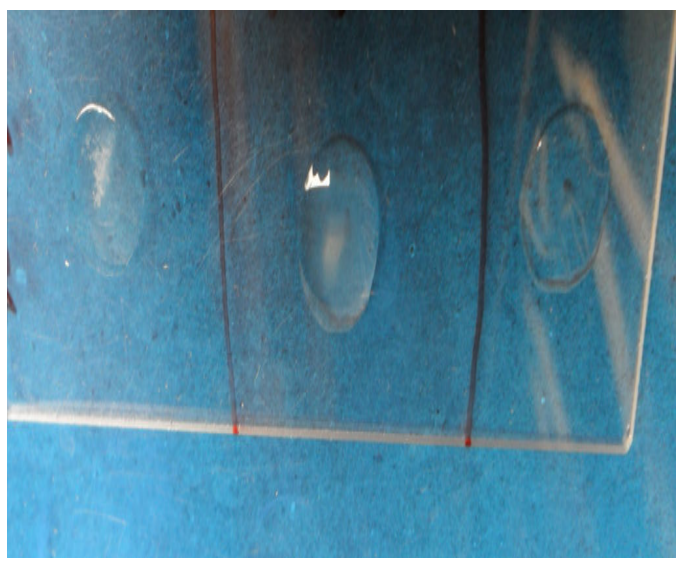

Figure 6. Slide agglutination test of sera of cattle at Day 90 (Pabna) showed clump formation within 5 min, graded as +++ in 1: 100 dilutions

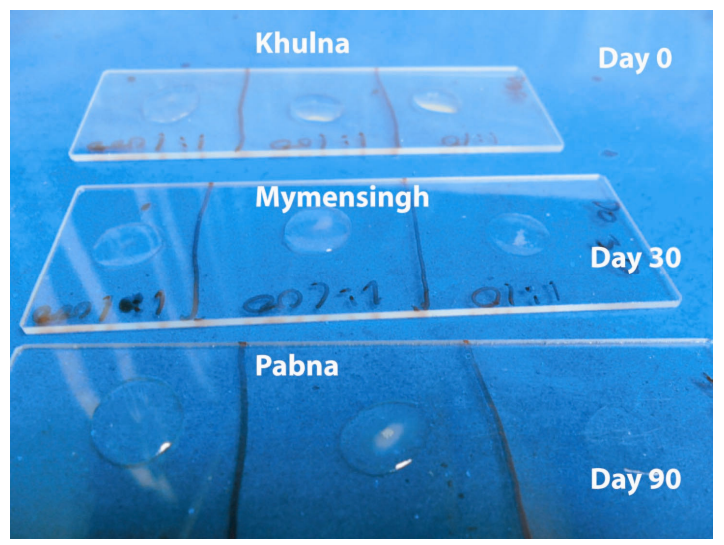

Figure7.Comparison of clumpingreaction of antigen (vaccine strain) with test sera of experimental cattle of Khulna, Mymensingh and Pabna of Day 0, Day 30 and Day 90 in $1: 10,1: 100$ and $1: 1000$ dilutions

Table 2. I-ELISA results of sera samples collected from experimental areas (Satkhira, Khulna, Pubna, Tangail and Mymensingh): OD value (Mean \pm SD)

\begin{tabular}{|cccc|}
\hline Sample & Day 0 & Day 30 & Day 90 \\
\hline Cattle 1 & $0.39 \pm 0.01$ & $0.79 \pm 0.01$ & $0.99 \pm 0.05$ \\
Cattle 2 & $0.37 \pm 0.03$ & $0.86 \pm 0.01$ & $0.97 \pm 0.02$ \\
Cattle 3 & $0.41 \pm 0.12$ & $0.75 \pm 0.04$ & $1.08 \pm 0.01$ \\
Cattle 4 & $0.47 \pm 0.01$ & $0.78 \pm 0.03$ & $0.97 \pm 0.04$ \\
Cattle 5 & $0.38 \pm 0.02$ & $0.83 \pm 0.02$ & $1.12 \pm 0.03$ \\
\hline
\end{tabular}

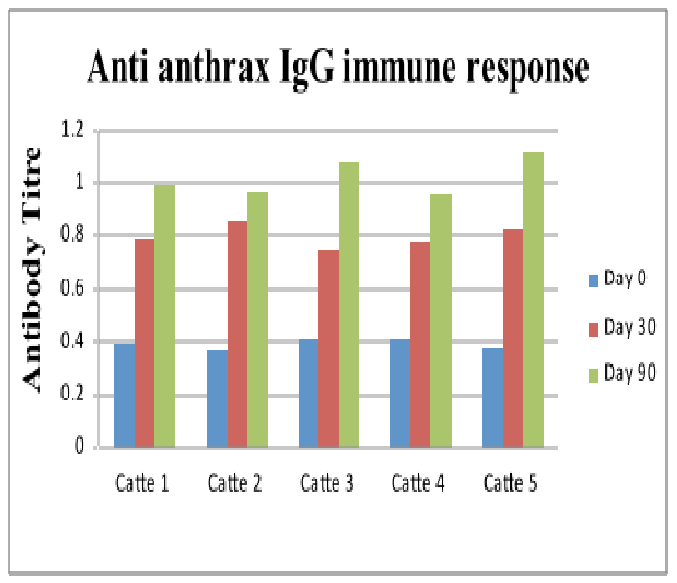

Figure8. Evaluation of serum anti anthrax $\operatorname{IgG}$ antibody response in sera of experimental cattle of Mymensingh in which theanti anthrax IgG wasdetected inday 30 of immunization, reached its peak at day 90

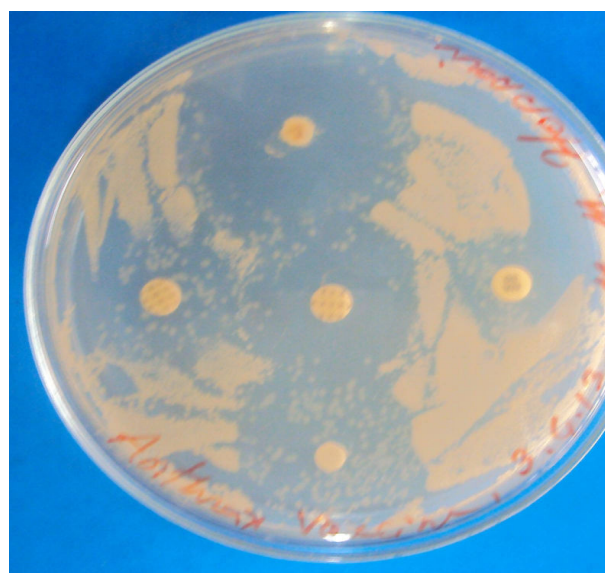

Figure9. Vaccine strain of Bacillus anthracis showed sensitivity to penicillin, streptomycin, amoxicillin and kenamycin. 
In $1 \%$ polychrome methylene blue stained slides the blue-black bacilli were seen with pink amorphous capsule (suspicious) under microscope i.e. the McFadyean reaction: characteristics of the Brucella anthracis (Murshidul, 2012).

In this study, slide agglutination test were done in cattle of climatic change prone delta region (Satkhira, Khulna) and semi changeable climatic zone of (Pabna, Tangail and Mymensingh) for observing the clumping/agglutination between antigen (vaccine strain) and test sera. The clumping observed for 5-15 min at room temperature. This agglutination test proved that the test sera contained specific antibody against anthrax antigen which was absent in Day 0 (negative) test sera. In this study, antibody response started rising at Day 30 and peaked up to Day 90. Similar results were also reported by others (Kok et al., 1996;Fatema, 2011). However, in this study no striking difference of immune response was found in cattle of climatic change prone delta region (Satkhira, Khulna) and semi changeable climatic zone of (Pabna, Tangail and Mymensingh).

The anthrax vaccine which is being used in the field to prevent the occurrence of anthrax in cattle appeared safe as there was no noticeable reaction of the host following immunization. The cattle did not reveal any agitation, swelling and rise of temperature following vaccination. The detectable level of anti $\operatorname{IgG}$ antibody response were seen in cattle following 30(0.78 \pm 0.01$)$ days after immunization and reached its peak in study Day $90(0.99 \pm 0.05)$. Such a finding is in consistence with that of Fatema (2011) who evaluated the effect of anthrax vaccine on cattle by measuring anti anthrax immune response with ELISA. In this investigation, the role of climate change in the virulence of the field isolates of $B$. anthracis, comparison of response to antibiotic and immune response could not be well documented due to some unavoidable conditions.

\section{ACKNOWLEDGEMENT}

The authors are grateful to Planning Commission, Bangladesh for financial support of this research work.

\section{REFERENCES}

1. Bergey DH, Holt JG, Krieg NR, Peter HA and Sneath (1994). Bergey's Manual of Determinative Bacteriology (9th ed.). Lippincott Williams \& Wilkins.

2. Fatema TZ (2011). Standerdization of an ELISA protocol for the detection of IgG antidody in cattle against anthrax vaccine. MS Thesis submitted to Dept. of Pathology, BAU, Bangladesh. pp. 45-55.

3. Koch R (1876). Investigations into bacteria: V. The etiology of anthrax, based on the ontogenesis of Bacillus anthracis. Cohns Beitrage zur Biologie der Pflanzen 2 :277-310.

4. Kok TW, Worswick D, Gowans E (1996). Some serological techniques for microbial and viral infections. Mackie \& McCartney. Practical Medical Microbiology. 14th ed,pp. 179-204.

5. Murshidul A (2012). Epidemiological investication of anthrax in Bangladesh. MS Thesis submitted to Dept. of Microbiology, BAU, Bangladesh. pp 23-48.

6. OIE Terrestrial Manual (2008). OIE listed diseases and other diseases of importance to international trade. Part-2, Chapter 2-1.1.Anthrax. pp. 135-144.

7. Weiss MM, Weiss PD and Weiss JB (2007): Anthrax vaccine and public health policy. American-Journalof-Public-Health 97(11) : 1945-1951 